SHORT REPORT

\title{
A new locus for hereditary haemorrhagic telangiectasia (HHT3) maps to chromosome 5
}

\author{
S G Cole, M E Begbie, G M F Wallace, C L Shovlin
}

J Med Genet 2005;42:577-582. doi: 10.1136/jmg.2004.028712

Patients with hereditary haemorrhagic telangiectasia (HHT, or Osler-Weber-Rendu syndrome) have variable presentation patterns and a high risk of preventable complications. Diagnostic tests for mutations in endoglin (HHT type 1) and ALK-1 (HHT type 2) are available. Some HHT patients are now known to have HHT-juvenile polyposis overlap syndrome due to Smad4 mutations. Families were ascertained following the presentation of probands for embolization of pulmonary arteriovenous malformations. Genome-wide linkage studies using over 700 polymorphic markers, and sequencing of candidate genes, were performed. In a previously described HHT family unlinked to endoglin or ALK-1, linkage to Smad4 was excluded, and no mutations were identified in the endoglin, $A L K-1$, or Smad4 genes. Two point LOD scores and recombination mapping identified a $5.4 \mathrm{cM}$ HHT3 disease gene interval on chromosome 5 in which a single haplotype was inherited by all affected members of the pedigree. The remainder of the genome was excluded to a 2-5 cM resolution. We are currently studying a further family potentially linked to HHT3. We conclude that classical HHT with pulmonary involvement can result from mutations in an unidentified gene on chromosome 5 . Identification of HHT3 should further illuminate HHT pathogenic mechanisms in which aberrant transforming growth factor (TGF)- $\beta$ signalling is implicated.

$\mathrm{H}$ ereditary haemorrhagic telangiectasia (HHT, also known as Osler-Weber-Rendu syndrome) is one of the most common autosomal dominant disorders, affecting between 1 in 5000 and 1 in 8000 people in Europe and Japan. ${ }^{2}$ HHT is a genetically heterogeneous group of disorders that lead to common vascular phenotypes. HHT types 1 and 2 have been recognised for more than a decade. HHTI (OMIM 187300) results from mutations in endoglin ${ }^{3}$ on chromosome 9, whereas the disease gene for HHT2 (OMIM 600376) is ALK-1 on chromosome $12 .{ }^{4}$ In addition, mutations in Smad4/MADH4 causing a juvenile polyposis/HHT overlap syndrome (JPHT; OMIM 175050) have been described recently..$^{5}$ Although the existence of a third "pure" HHT locus has been suggested twice, ${ }^{67}$ the first family were subsequently demonstrated to have an $A L K-1$ mutation, ${ }^{8}$ and further data on the family described by Wallace and Shovlin ${ }^{7}$ have not been presented.

All forms of HHT result in the development of abnormal blood vessels including telangiectasia of the oral mucous membranes, nose, and gastrointestinal tract, and visceral arteriovenous malformations (AVMs). Nosebleeds and chronic gastrointestinal bleeding leading to iron deficiency anaemia and transfusion dependence are the features of HHT most appreciated by clinicians. Visceral AVMs are usually silent, but screening programmes indicate that pulmonary
AVMs occur in $30-50 \%$ of HHT patients, ${ }^{9}{ }^{10}$ cerebral AVMs in $10 \%,{ }^{9}$ and hepatic AVMs in 20-30\%. ${ }^{611}$ Pulmonary AVMinduced embolic strokes and brain abscesses, and cerebral AVM-induced haemorrhagic strokes make HHT a common cause of inherited stroke in young adults, ${ }^{12}$ and complications from other visceral involvement, including hepatic failure, also occur. There are subtle differences in the phenotype between HHT1 and HHT2, with HHT2 patients exhibiting fewer pulmonary AVMs and a milder HHT phenotype, ${ }^{13}$ but carrying a higher risk of development of HHT related pulmonary arterial hypertension ${ }^{14}$ (table 1).

Importantly, many of the complications of HHT can be prevented or limited by clinical screening programmes. Since HHT is a disease with late onset penetrance $(\approx 90 \%$ by 40 years; $97 \%$ by 60 years ${ }^{15}$ ), genetic screening programmes have been introduced. ${ }^{16}$ Patients without detectable mutations in endoglin or ALK-1 are recognised by the HHT genetic centres. It would be predicted that some of these, particularly from smaller families will have Smad4 mutations since routine colonoscopies that would exclude juvenile polyposis are not a feature of HHT management. In this group, there would be additional clinical screening implications, since for at risk members of juvenile polyposis (JP) families, the British Society of Gastroenterology recommends surveillance colonoscopies and upper gastrointestinal endoscopies, with therapeutic interventions to reduce later risks of colon cancer. ${ }^{17}$

The pathogenic mechanisms involved in the development of the HHT vessels are of interest to scientists and clinicians alike. Endoglin and $A L K-1$ encode proteins expressed predominantly on vascular endothelial cells. Endoglin, ALK-1, and the ubiquitously expressed Smad4 are involved in signalling by the transforming growth factor (TGF)- $\beta$ superfamily that regulates a diverse series of fundamental pathways in development and pathophysiology. A simplified model of Smad dependent signalling by this superfamily is presented in fig 1, indicating the interactions and functions of the HHT gene products. Ligands signal through heteromeric complexes comprised of type I and type II cell surface receptor serine-threonine kinases. ${ }^{18}$ Activated type I receptors phosphorylate cytoplasmic receptor associated Smad proteins (R-Smads). These oligomerise with a co-Smad molecule, Smad4, and translocate to the nucleus to act as transcription factors and alter gene expression.

In view of the clinical implications of the new molecular association of HHT with juvenile polyposis, we consider it important to report the linkage analysis in the classical HHT pedigree described by Wallace and Shovlin. ${ }^{7}$ This identifies a

Abbreviations: AVMs, arteriovenous malformations; CM-AVM, capillary malformation-arteriovenous malformation; EBV, Ebstein-Barr virus; EC, endothelial cells; $\mathrm{HBT}$, hereditary benign telangiectasia; $\mathrm{HHT}$, hereditary haemorrhagic telangiectasia; HHT1, HHT type 1; HHT2, HHT type 2; JP, juvenile polyposis; JPHT, juvenile polyposis/HHT overlap syndrome; R-Smads, receptor-associated Smad proteins; TGF- $\beta$, transforming growth factor- $\beta$ 


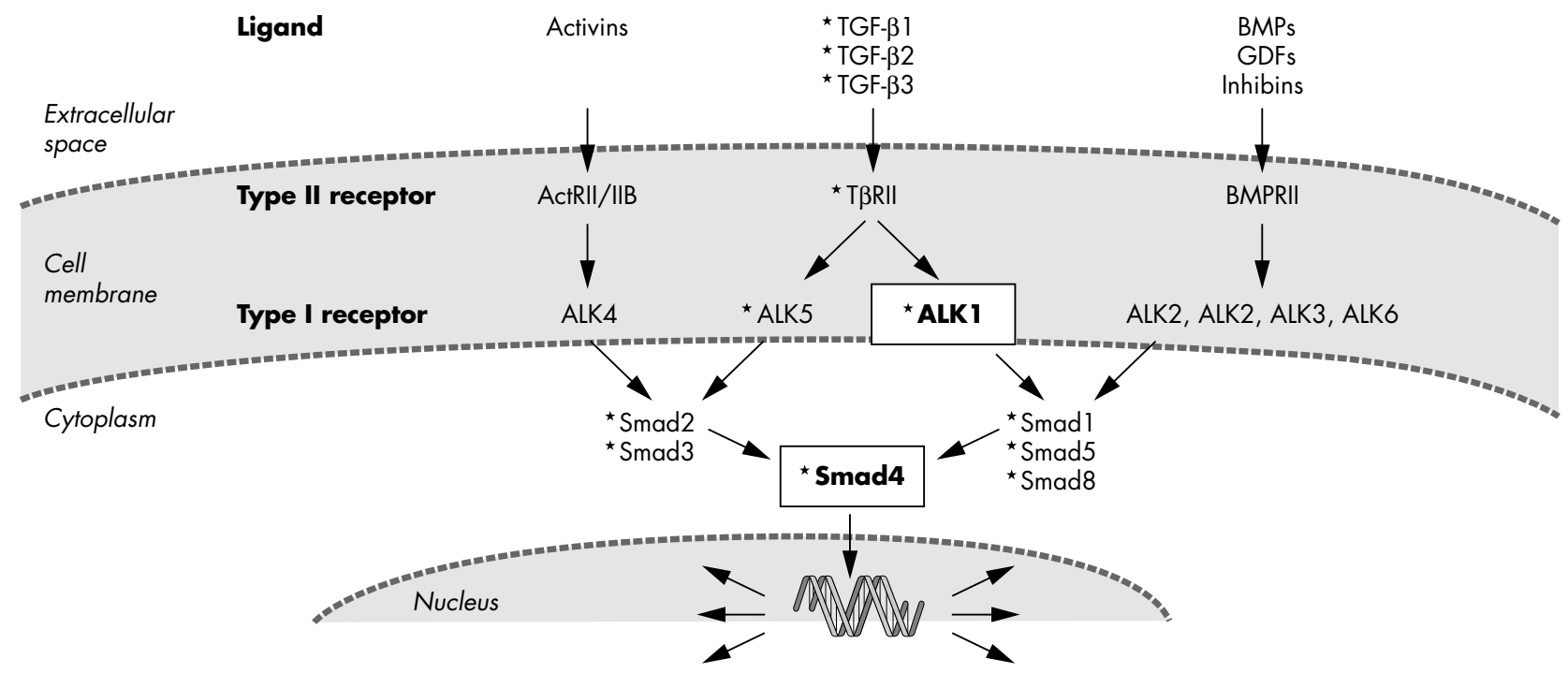

Figure 1 TGF- $\beta$ superfamily signalling in EC indicating roles of the known HHT gene products. Endoglin associates with all three groups of transmembrane signalling receptors ${ }^{27}$ and modulates TGF- $\beta 1$ induced cellular responses. ${ }^{28}$ Expression of ALK-1 on EC allows TGF- $\beta 1 / T \beta R$ II to transduce signals through Smad1 and Smad5, whereas in most cell types, TGF- $\beta /$ T $\beta R$ Rll initiate Smad2 and Smad3 signalling following activation of ALK-5. ${ }^{29}$ BMPs, bone morphogenetic proteins; GDF, growth/differentiation factors. Boxes: HHT gene products. *: gene excluded by linkage analyses.

new HHT gene locus (HHT3) on chromosome 5, resulting in four known types of HHT (table 1).

\section{METHODS \\ Pedigrees}

The proband (fig 2, III.3) was referred to the Hammersmith Hospital for embolization of pulmonary arteriovenous malformations (AVMs). Extended pedigree analysis was performed with informed consent and Multicentre and Local Research Ethics Committee approval (MREC/98/0/42; LREC 99/5637M). The diagnosis of HHT was assigned by the presence of three international consensus diagnostic criteria, ${ }^{19}$ that is: affected first degree relative; recurrent, spontaneous nosebleeds; mucocutaneous telangiectasia; and in the case of III.3 and III.4, documented visceral manifestations (pulmonary AVMs). Importantly, telangiectasia were considered diagnostic only if in the correct distribution for HHT (that is, nose, lips, tongue, oral mucosa, finger tips, or ears) and persistent, having developed from late childhood or during adult life. In view of nosebleeds affecting $8-10 \%$ of children, with nocturnal nosebleeds a common feature, ${ }^{20}$ occasional nosebleeds occurring purely in childhood were not considered a diagnostic criterion.

\section{Genotyping and molecular analyses}

Genomic DNA was extracted from peripheral venous blood or Isocode mouth swabs (Schleicher and Schuell, Dassel,
Germany) using standard procedures. cDNA was derived from Ebstein-Barr virus (EBV) immortalised lymphocyte cell lines which were established on four family members as previously. ${ }^{21}$

A total of 400 fluorescently labelled primer pairs from the ABI Prism Linkage MD-10 Mapping Set (Applied Biosystems, Foster City, CA) were used according to the manufacturer's instructions for a first genome-wide linkage screen. An additional 312 fluorescently labelled polymorphic markers pre-labelled from Applied Biosystems and Research Genetics (Huntsville, AL), or custom synthesised by Sigma-Genosys (Cambridge, UK), were used to fine-map the identified interval, and exclusion map the remainder of the genome. PCR products were size separated on a ABI 7700 capillary sequencer, and analysed using GeneScan software (Applied Biosystems). Candidate genes were analysed by PCR amplification of all exons, exon-intron boundaries, and 40-50 bp of flanking intronic sequence (endoglin, ALK-1, Smad4, Smad5), or by sequencing the entire cDNA from EBV immortalised lymphocyte cell lines (SPARC). Primer details are available on request.

Two point LOD scores between a putative disease locus and each marker were calculated assuming autosomal dominant inheritance, a disease gene frequency of 0.0001 , and equal recombination rates in both sexes. LOD scores were calculated initially with equal allele frequencies. Based on previously published estimates, ${ }^{152}$ for unaffected individuals,

Table 1 HHT genes and pattern of HHT

\begin{tabular}{|c|c|c|c|c|c|c|c|}
\hline HHT & HHT features & Inheritance & Comments on $\mathrm{HHT}$ & Disease associations & Chromosome & Gene & $\begin{array}{l}\text { Phenotype } \\
\text { references }\end{array}$ \\
\hline $\mathrm{HHTI}$ & Classical HHT & $A D$ & $\begin{array}{l}\text { Higher frequency of } \\
\text { pulmonary } A V M s\end{array}$ & & 9 & Endoglin ${ }^{3}$ & $\begin{array}{l}\text { Berg et al, }{ }^{13} \\
\text { Shovlin et al }{ }^{11}\end{array}$ \\
\hline HHT2 & Classical HHT & $A D$ & Milder phenotype & $\begin{array}{l}\text { Primary pulmonary } \\
\text { hypertension (PPH) }\end{array}$ & 12 & $A L K-1^{4}$ & $\begin{array}{l}\text { Berg et al, }{ }^{13} \\
\text { Trembath et al }{ }^{14}\end{array}$ \\
\hline JPHT & $\begin{array}{l}\text { Juvenile polyposis (JP) } \\
\text { associated with } \mathrm{HHT}\end{array}$ & $A D$ & & Juvenile polyposis & 18 & $\operatorname{Smad} 4^{5}$ & Gallione et $a^{5}$ \\
\hline HHT3 & Classical HHT & $A D$ & See text & & 5 & $?$ & Current \\
\hline
\end{tabular}

$A D$, autosomal dominant. 


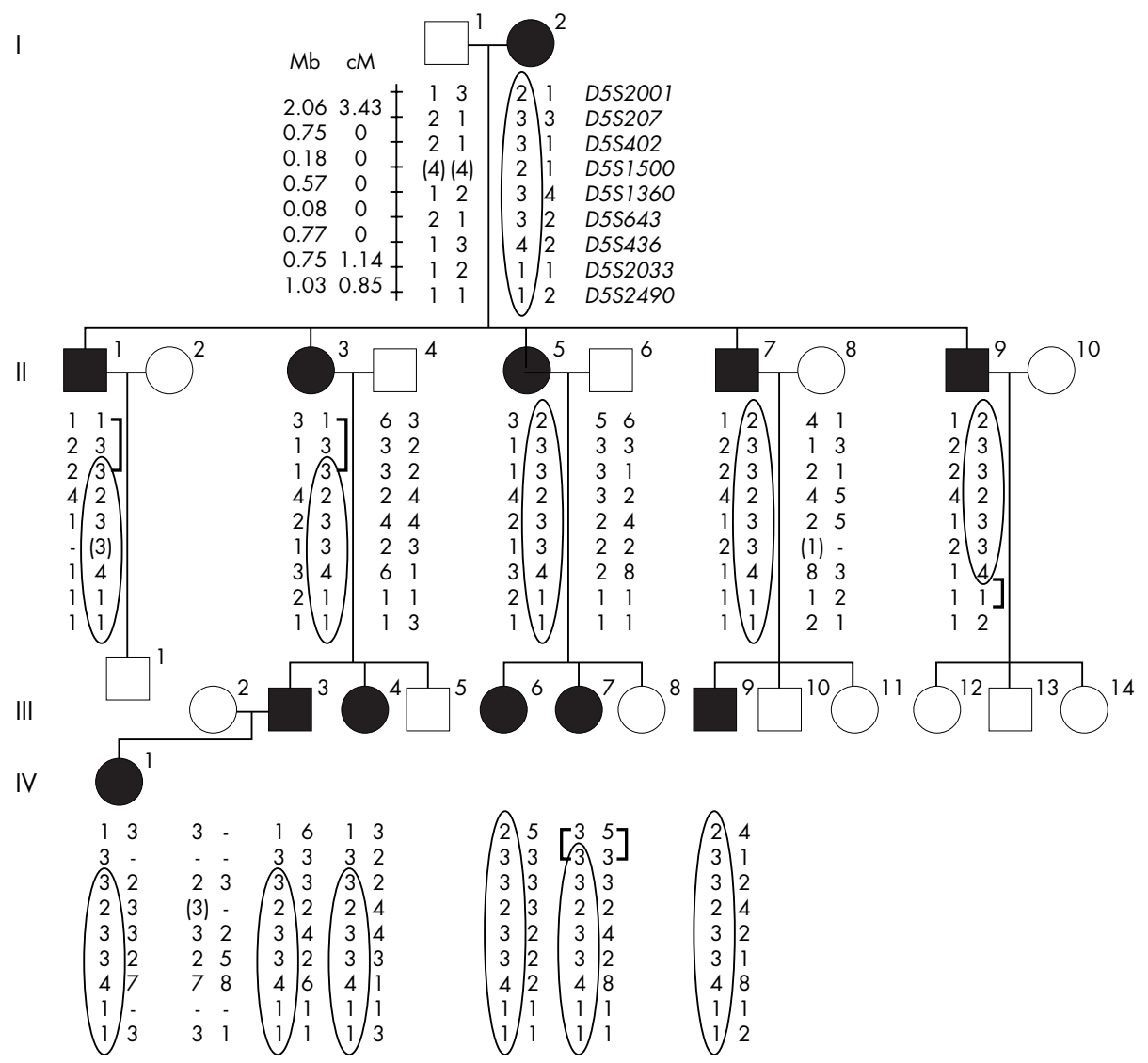

Figure 2 Family pedigree and haplotype analysis. Pedigree: Individuals III. 3 and III.4 have pulmonary AVMs. DNA from II.3, II.4, III.3, and III.4 was sequenced for candidate gene analyses. Haplotype analysis: Inheritance of 10 haplotypes in the pedigree indicates segregation of disease haplotype (outlined) in all affected individuals over four generations (II-V). Data on clinically unaffected individuals are not included for ethical reasons, and data on uninformative markers have been excluded for clarity. Key: [or]: recombination events; ( ): data deduced from offspring; -: data not available.

penetrance was set at $\mathrm{p}=0.8$ between ages 12 and 35 and $\mathrm{p}=0.95$ aged over 35 giving two liability classes. Apparently unaffected children under the age of 12 years were excluded as penetrance is less than $80 \%$ at this age. ${ }^{22}$ SLINK and MLINK analyses ${ }^{23}$ were performed using Human Genome Mapping Project (HGMP) computational resources. The order and distances between the markers were derived from Ensembl (http://www.ensembl.org/) and GenBank (http://www.ncbi.nlm.nih.gov/) databases.

\section{RESULTS}

\section{Exclusion of known HHT disease genes}

Linkage analyses were performed to confirm the exclusion of endoglin and $A L K-1$ in the extended pedigree, and to exclude the new JP-HHT gene, Smad4 (table 2).

Endoglin had been sequenced in full in affected members of the pedigree. ${ }^{21}$ The other two HHT genes were sequenced in four affected family members (III.3, II.3, II.4, III.3, and III.4). No mutations were found in any of the $A L K-1$ coding regions or intron-exon boundaries. Although the JP-HHT mutations predominantly occur in the $3^{\prime}$ exons of Smad4, ${ }^{5}$ all 11 exons and intron-exon boundaries were sequenced. No mutations were found.

\section{Exclusion of core components of the TGF- $\beta$ signalling pathways}

Recognising that the data from the other HHT genes strongly suggested that the disease gene in this pedigree would encode a protein affecting TGF- $\beta$ signalling, other core components of TGF- $\beta$ signalling pathways were excluded by linkage analyses (see fig 1). Literature and database searches revealed that in addition to the proteins illustrated in fig 1 , over 100 further proteins are known to interact with the TGF- $\beta$ superfamily signalling pathways, precluding an exhaustive candidate gene approach. A genome-wide screen was therefore undertaken.

\section{Linkage analyses define the HHT3 locus on chromosome 5}

An initial genome-wide scan excluded $70 \%$ of the genome, and identified a $12 \mathrm{cM}$ interval where LOD scores exceeded +2 . Information from initial markers was limited due to noninformative meioses. Supplementary adjacent markers were fully informative, generating a two point $Z_{\max }$ of 3.45 at a recombination fraction $(\theta)$ of 0.00 , and refining the interval. LOD scores were robust to changes in allele frequency (data not shown). The SLINK theoretical $Z_{\max }$ of 4.84 at $\theta=0.00$ was not achieved due to recombination events in clinically unaffected individuals. The series of two point LOD scores (table 3 ) and recombination mapping using affected individuals (fig 3) defined the $5.4 \mathrm{cM} / 6 \mathrm{Mb}$ HHT3 locus. In this region, all affected family members had inherited a conserved disease associated haplotype (fig 2).

In order to assess the likely frequency of HHT3, we studied three families (including two previously unreported) with theoretical $\mathrm{Z}_{\max }>1.6$ in which assignment to endoglin or $A L K$ 1 could not be made. In two, linkage to HHT3 was excluded. In a third family with a theoretical $Z_{\max }$ of 1.87 , a maximum two point LOD score of 1.17 at $\theta=0.00$ was obtained with D5S436 on a different disease-segregating haplotype to that 
Table 2 Exclusion of known HHT genes

\begin{tabular}{|c|c|c|c|c|c|c|}
\hline & $M b$ & $c M$ & $\theta=0.00$ & $\theta=0.05$ & $\theta=0.10$ & $\theta=0.50$ \\
\hline D9S1682 & 120 & 132 & -9.88 & -3.58 & -2.14 & 0.00 \\
\hline Endoglin & 124 & 136 & & & & \\
\hline D9S1825 & 125 & 137 & -11.38 & -4.59 & -2.95 & 0.00 \\
\hline D12S85 & 46 & 61 & -6.98 & -5.99 & -4.14 & 0.00 \\
\hline$A L K-1$ & 50 & 65 & & & & \\
\hline D12S359 & 52 & 68 & -10.60 & -5.83 & -4.93 & 0.00 \\
\hline D18S363 & 47 & 71 & -22.1 & -3.66 & -2.30 & 0.00 \\
\hline Smad4 & 47 & 71 & & & & \\
\hline D18S112 & 52 & 77 & -21.9 & -4.06 & -2.64 & 0.00 \\
\hline \multicolumn{7}{|c|}{$\begin{array}{l}\text { Haplotype and multipoint data for endoglin and } A L K-1 \text { are presented in } \\
\text { Wallace and Shovlin. } M b \text { and } C M \text { refer to position on respective } \\
\text { chromosome. }\end{array}$} \\
\hline
\end{tabular}

illustrated in fig 2 . The reduction from the theoretical $Z_{\max }$ was due to a single young unaffected recombinant.

\section{Exclusion mapping}

To exclude the possibility that an alternative locus had been missed, the remainder of the genome was formally examined. A further 290 polymorphic markers were selected and analysed to ensure that at least two double recombination events would have had to occur in a $2-5 \mathrm{cM}$ interval for a putative locus to have been missed. Highly conservative estimates (excluding genetic interference) based on 500 intervals indicated that the probability of this occurring was between $3.1 \times 10^{-3}$ and $8 \times 10^{-5}$ (that is, $\mathrm{p} \leqslant 0.0031$ ).

\section{Candidate gene analysis}

Ensembl identifies 28 genes within the $5.4 \mathrm{cM} H H T 3$ interval, including 10 of unknown function. Furthermore, the gene for Smad5, a strong candidate based on its role in ALK-1 signalling pathways (fig 1), is assigned on current mapping to within $5 \mathrm{Mb}$ of the HHT3 interval (fig 3). The Smad5 gene had been excluded by linkage analyses using markers either side of the published gene locus. However, in view of its strong candidate status due to functional considerations, and the possibility that the precise database positional assignment of Smad5 was erroneous, all coding exons and flanking intronic sequence were sequenced in affected members of both families. No pathogenic mutations were identified. In addition, the initial $12 \mathrm{cM}$ mapping interval contained $S P A R C$, a further attractive candidate gene due to endothelial cell expression and roles in TGF- $\beta 1$ mediated proliferative responses. ${ }^{24}$ SPARC cDNA was amplified from EBV immortalised lymphocyte cell lines. The complete transcript was sequenced and no mutations identified.

\section{DISCUSSION}

We have identified a novel locus for the autosomal dominant disorder hereditary haemorrhagic telangiectasia (HHT). In the presented family, the disease affects both sexes equally and is indistinguishable from that in other families with HHT. The pulmonary AVM frequency (13\%) was not as high as in HHT type I families with endoglin mutations, but numbers are too small to suggest that HHT3 resembles HHT2 more than HHTl. Importantly, no family members have experienced cancer of any form, and none are known to have developed pulmonary hypertension.

Our data do not allow us to address the proportion of HHT families which are due to HHT3, as in our four "unassigned" large families, only one categorically maps to chromosome 5. Most HHT families will have mutations in endoglin or ALK-1, and mutational screening programmes should detect the majority of these. Data from labs employing sensitive quantitative genomic exon PCR screening methods have not detected mutations in as many as $10-15 \%$ of classical HHT families (Dr Michelle Letarte, personal communication). In these families, linkage analyses with the chromosome 5 markers should begin to address the likely frequency of HHT3.

The HHT3 locus $(5 \mathrm{q} 31.3-5 \mathrm{q} 32)$ is not the same as that recently identified for hereditary benign telangiectasia (HBT; OMIM 187260) on chromosome 5 (5q14), ${ }^{25}$ for which the causative gene, RASAl, encoding Ras GTPase activating protein 1 , has been identified. ${ }^{26}$ HBT is therefore part of the capillary malformation-arteriovenous malformation (CMAVM) syndrome, ${ }^{26}$ and should not be considered a benign allelic variant of HHT as proposed. ${ }^{25}$ The importance of making this clear distinction is that HHT patients are at significant risk of pulmonary and cerebral AVMs. The diseases can be distinguished clinically by the distinctive skin lesions. In $\mathrm{HBT}$, randomly distributed cutaneous vascular malformations over the head, trunk, and limbs are often congenital $(40 \%)$ or develop from early childhood. In contrast, HHT telangiectasia have a highly restricted distribution on the mucosa of the nose, lips, oral cavity, conjunctiva, finger tips, ears, and face, ${ }^{19}$ develop from teenage years, and become more numerous with age.

As all three identified HHT genes encode proteins involved in TGF- $\beta$ superfamily signalling, we anticipate that the disease gene responsible for HHT3 will also encode a protein involved in Smad dependent TGF- $\beta$ signalling. In keeping with the expression patterns of endoglin and ALK-1 which are transmembrane proteins predominantly expressed on vascular endothelial cells (EC), we predict that the disease gene for this "pure" form of HHT will also display EC restricted expression. Identification of this gene will be

Table 3 LOD scores (Z) spanning the HHT3 interval

\begin{tabular}{|c|c|c|c|c|c|c|c|c|c|c|}
\hline Marker & $c M$ & $\mathrm{Mb}$ & 0 & 0.01 & 0.05 & 0.1 & 0.2 & 0.3 & 0.4 & 0.5 \\
\hline D5S2011 & 144.06 & 141.25 & -8.82 & -2.55 & -0.58 & 0.15 & 0.64 & 0.67 & 0.44 & 0.00 \\
\hline D5S2017 & 145.21 & 141.76 & -3.76 & 0.19 & 0.79 & 0.95 & 0.91 & 0.68 & 0.36 & 0.00 \\
\hline D5S1972 & 146.73 & 142.37 & 1.44 & 1.43 & 1.39 & 1.31 & 1.07 & 0.72 & 0.32 & 0.00 \\
\hline D5S207 & 147.49 & 143.31 & 1.72 & 1.71 & 1.67 & 1.59 & 1.35 & 1.01 & 0.56 & 0.00 \\
\hline D5S402 & 147.49 & 144.06 & 2.42 & 2.40 & 2.30 & 2.15 & 1.74 & 1.21 & 0.58 & 0.00 \\
\hline D5S1480 & 147.49 & 144.17 & 1.72 & 1.71 & 1.67 & 1.59 & 1.35 & 1.01 & 0.56 & 0.00 \\
\hline D5S1500 & 147.49 & 144.24 & 3.10 & 3.06 & 2.88 & 2.64 & 2.09 & 1.43 & 0.69 & 0.00 \\
\hline D5S210 & 147.49 & 144.49 & 2.24 & 2.23 & 2.16 & 2.03 & 1.70 & 1.25 & 0.69 & 0.00 \\
\hline D5S1360 & 147.49 & 144.92 & 3.00 & 2.97 & 2.84 & 2.64 & 2.13 & 1.49 & 0.74 & 0.00 \\
\hline D5S643 & 147.49 & 145.00 & 3.45 & 3.41 & 3.25 & 3.01 & 2.42 & 1.69 & 0.84 & 0.00 \\
\hline D5S436 & 147.49 & 145.23 & 3.45 & 3.41 & 3.25 & 3.01 & 2.42 & 1.69 & 0.84 & 0.00 \\
\hline D5S2033 & 148.63 & 145.98 & 0.40 & 0.46 & 0.59 & 0.65 & 0.62 & 0.49 & 0.28 & 0.00 \\
\hline D5S2847 & 149.48 & 147.00 & -2.60 & 1.34 & 1.83 & 1.87 & 1.59 & 1.14 & 0.59 & 0.00 \\
\hline D5S2490 & 149.48 & 147.01 & -4.12 & -0.16 & 0.43 & 0.58 & 0.57 & 0.40 & 0.19 & 0.00 \\
\hline D5S670 & 156.47 & 152.88 & -3.90 & -1.90 & -0.55 & -0.03 & 0.34 & 0.38 & 0.25 & 0.00 \\
\hline
\end{tabular}



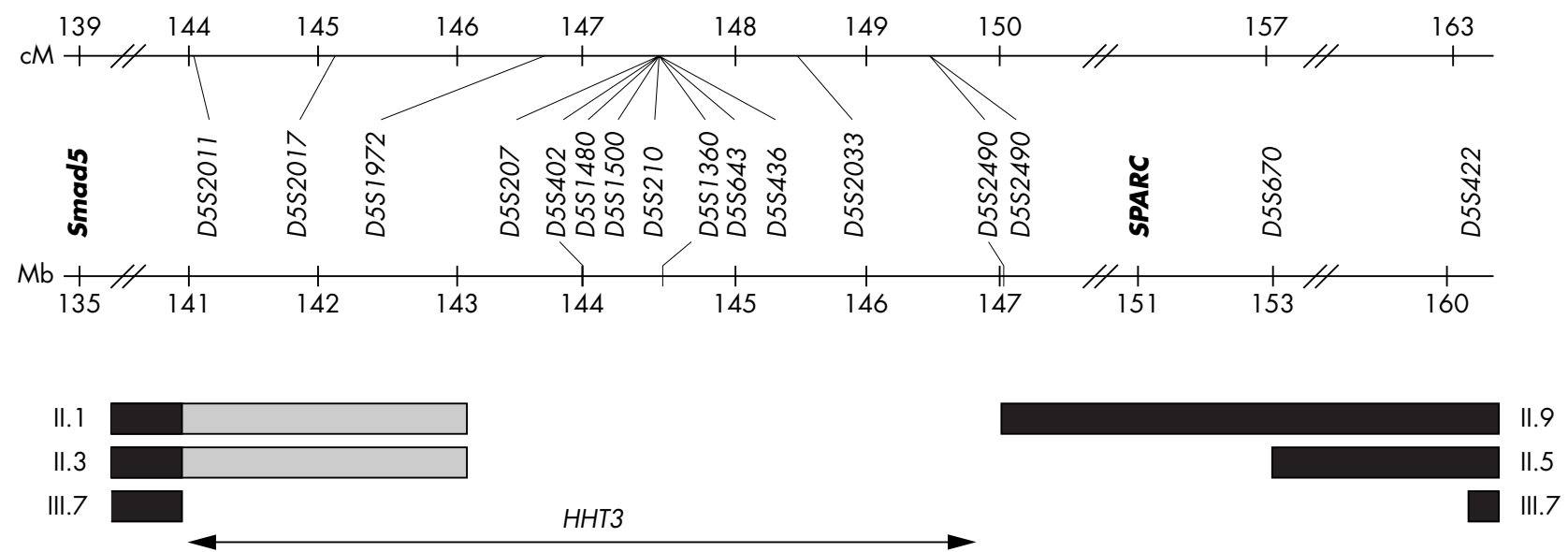

Figure 3 Recombination mapping of interval using affected family members. Pedigree numbers as in fig 2. Black bars indicate definite recombination events; shaded bars indicate uninformative markers. The locations of the candidate genes Smad5 and SPARC (but not RASA1 at $86.6 \mathrm{Mb}$ ) are illustrated.

important not only for clinical diagnostic services but also to elucidate the mechanisms of TGF- $\beta$ superfamily signalling in vascular endothelium.

\section{ACKNOWLEDGEMENTS}

We are grateful to the families for their participation in these studies, the MRC-CSC Core Sequencing Facility at Hammersmith, Dr Carol Shoulders for provision of approximately 100 polymorphic markers, Dr Anna Marrone for assistance in the establishment of the EBV immortalised cell lines and Dr Julian Walters for discussions on juvenile polyposis phenotype and screening. We also thank Dr Carol Shoulders, Professor Anne Soutar, Dr Bernard Morley, and Dr Michael Jones for helpful discussions and draft manuscript reviews.

\section{ELECTRONIC-DATABASE INFORMATION}

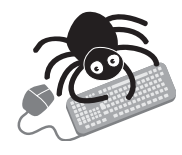

The Ensembl website can be found at http:// www.ensembl.org/ and GenBank at http:// www.ncbi.nlm.nih.gov/.

\section{Authors' affiliations}

S G Cole, C L Shovlin, The Eric Bywaters Centre, Respiratory Section, National Heart and Lung Institute, Imperial College Faculty of Medicine, Hammersmith Hospital, London W12 ONN, UK

M E Begbie, Respiratory Medicine, National Heart and Lung Institute, Imperial College Faculty of Medicine, Hammersmith Hospital, London W12 ONN, UK

G M F Wallace, Respiratory Medicine Unit, University of Edinburgh, Edinburgh, UK

This project was primarily funded by the British Heart Foundation, with additional support from the Margaret Hayton HHT Memorial Fund.

Competing interests: none declared

Correspondence to: Dr Claire Shovlin, The Eric Bywaters Centre, Respiratory Section, National Heart and Lung Institute, Imperial College Faculty of Medicine, Hammersmith Hospital, Du Cane Road, London W12 ONN, UK; c.shovlin@imperial.ac.uk

Received 1 November 2004

Revised version received 14 December 2004

Accepted for publication 15 December 2004

\section{REFERENCES}

1 Kjeldsen AD, Vase P, Green A. Hereditary hemorrhagic telangiectasia (HHT): a population-based study of prevalence and mortality in Danish HHT patients. $J$ Intern Med 1999;245:31-9.

2 Dakeishi M, Shioya T, Wada Y, Shindo T, Otaka K, Manabe M, Nozoki J, Inoue S, Koizumi A. Genetic epidemiology of hereditary haemorrhagic telangiectasia in a local community in the northern part of Japan. Hum Mutat 2002;19:140-8.

3 McAllister KA, Grogg KM, Johnson DW, Gallione CJ, Baldwin MA Jackson CE, Helmbold EA, Markel DS, McKinnon WC, Murrell J, McCormick MK, Pericak-Vance MA, Heutink P, Oostra BA, Haitjema T, Westerman CJJ, Porteous ME, Guttmacher AE, Letarte M, Marchuk DA Endoglin, a TGF- $\beta$ binding protein of endothelial cells, is the gene for hereditary haemorrhagic telangiectasia type 1. Nat Genet 1994;8:345-51.

4 Johnson DW, Berg JN, Baldwin MA, Gallione CJ, Marodel I, Yoon S-J, Stenzel TT, Speer M, Pericak-Vance MA, Diamond A, Guttmacher AE, Jackson CE, Attisano L, Kucherlapati R, Porteous MEM, Marchuk DA. Mutations in the activin receptor-like kinase 1 gene in hereditary haemorrhagic telangiectasia type 2. Nat Genet 1996;13:189-95

5 Gallione C, Repetto GM, Legius E, Rustgi AK, Schelley SL, Tejbar S, Mitchell G, Drouin E, Westermann C, Marchuk D. A combined syndrome of juvenile polyposis and hereditary haemorrhagic telangiectasia is associated with mutations in MADH4 (SMAD4). Lancet 2004;363:852-9.

6 Piantanida M, Buscarini E, Dellavecchia C, Minelli A, Rossi A, Buscarini L, Danesino $C$. Hereditary haemorrhagic telangiectasia with extensive liver involvement is not caused by either HHT1 or HHT2. J Med Genet 1996:33:441-3

7 Wallace GMF, Shovlin CL. A hereditary haemorrhagic telangiectasia family with pulmonary involvement is unlinked to the known HHT genes, endoglin and ALK-1. Thorax 2000;55:685-90.

8 Olivieri C, Mira E, Delu G, Pagella F, Zambelli A, Malvezzi L, Buscarini E, Danesino C. Identification of 13 new mutations in the ACVRL1 gene in a group of 52 unselected Italian patients affected by hereditary haemorrhagic telangiectasia. J Med Genet 2002;39:e39.

9 Haitjema T, Disch F, Overtoom TTC, Westermann CJ, Lammers J-WJ. Screening family members of patients with hereditary haemorrhagic telangiectasia. Am J Med 1995;99:519-24.

10 Kjeldsen A, Oxhoj H, Andersen P, Green A, Vase P. Prevalence of pulmonary arteriovenous malformations (PAVMs) and occurrence of neurological symptoms in patients with hereditary haemorrhagic telangiectasia. $J$ Intern Med 2000;248:255-62.

11 McDonald J, Miller FJ, Hallam SE, Nelson L, Marchuk DA, Ward KJ. Clinical manifestations in a large hereditary hemorrhagic telangiectasia (HHT) type 2 kindred. Am J Med Genet 2000;93:320-7.

12 Begbie ME, Wallace GMF, Shovlin CL. Hereditary haemorrhagic telangiectasia (Osler-Weber-Rendu syndrome): a view from the 21 st century Postgrad Med J 2003;79:18-24.

13 Berg JN, Porteous MEM, Reinhardt D, Gallione C, Holloway S, Masunthar T, Lux A, McKinnon W, Marchuk DA, Guttmacher AE. Hereditary haemorrhagic telangiectasia: a questionnaire based study to delineate the different phenotypes caused by endoglin and ALK 1 mutations. J Med Genet 2003;40:585-90.

14 Trembath R, Thomson J, Machado R, Morgan N, Atkinson C, Winship I, Simonneau G, Galie N, Loyd J, Humbert M, Nichols W, Morrell N. Clinical and molecular features of pulmonary hypertension in hereditary hemorrhagic telangiectasia. N Engl J Med 2001;345:325-34.

15 Plauchu H, de Chadarévian J-P, Bideau A, Robert J-M. Age-related profile of hereditary hemorrhagic telangiectasia in an epidemiologically recruited population. Am J Med Genet 1989;32:291-7.

16 Hereditary Haemorrhagic Telangiectasia Foundation International. DNA screening test now available for all families with HHT. In: Direct Connection. Monkton, MD: Hereditary Haemorrhagic Telangiectasia Foundation International, Winter, 2003:1-2.

17 Dunlop MG. British Society of Gastroenterology: Guidance on gastrointestinal surveillance for hereditary non-polyposis colorectal cancer, familial adenomatous polyposis, juvenile polyposis and Peutz-Jeghers syndrome. Gut 2002;51(Suppl V):v21-7. 
18 Miyazono K, Kusanagi K, Inoue $H$. Divergence and convergence of TGF- $\beta$ / BMP signaling. J Cell Physiol 2001;187:265-76.

19 Shovlin CL, Guttmacher AE, Buscarini E, Faughan M, Hyland R, Westermann CJJ, Kjeldsen AD, Plauchu $H$. Diagnostic criteria for hereditary haemorrhagic telangiectasia (Rendu-Osler-Weber syndrome). Am J Med Genet 2000:91:66-7.

20 Makura ZGG, Porter GC, McCormick MS. Paediatric epistaxis: Alder Hey experience. J Laryngol Otol 2002;116:903-6.

21 Shovlin CL, Hughes JMB, Scott J, Seidman CE, Seidman JG. Characterization of endoglin and identification of novel mutations in hereditary hemorrhagic telangiectasia. Am J Med Genet 1997:61:68-79.

22 Shovlin CL, Hughes JMB, Tuddenham EGD, Temperley I, Perembelon YFN, Scott J, Seidman CE, Seidman JG. A gene for hereditary haemorrhagic telangiectasia maps to chromosome 9q3. Nat Genet 1994;6:205-9.

23 Ott J. Analysis of human genetic linkage. 2nd ed. Baltimore, MD: Johns Hopkins University Press, 1992.

24 Schieman BJ, Neil JR, Schiemann WP. SPARC inhibits epithelial cell proliferation in part through stimulation of the transforming growth factorbeta-signaling system. Mol Biol Cell 2003;14:3977-88.
25 Brancati F, Valente EM, Tadini G, Capouto C, Benetto AD, Gelmetti C Dallapiccola $B$. Autosomal dominant hereditary benign telangiectasia maps to the CMC1 locus for capillary malformation on chromosome $5 q 14$. J Med Genet 2003:40:849-53.

26 Eerola I, Boon LM, Mulliken JB, Burrows PE, Dompmartin A, Watanabe S, Vanwijck R, Vikkula M. Capillary malformation-arteriovenous malformation, a new clinical and genetic disorder caused by RASAl mutations. Am J Hum Genet 2003;73:1240-9.

27 Pece Barbara N, Wrana JL, Letarte M. Endoglin is an accessory protein that interacts with the signaling receptor complex of multiple members of the transforming growth factor- $\beta$ superfamily. J Biol Chem 1999;274: 584-94.

28 Letamandía A, Lastres P, Botella L, Raab U, Langa C, Velasco B, Attisano L, Bernabeu $C$. Role of endoglin in cellular responses to transforming growth factor- $\beta$. J Biol Chem 1998;273:33011-9.

29 Goumans MJ, Lebrin F, Valdimarsdottir G. Controlling the angiogenic switch: a balance between two distinct TGF- $\beta$ receptor signaling pathways. Trends Cardiovasc Med 2003;13:301-7.

\section{CORRECTION}

doi: 10.1136/jmg.2005.19224corr 1

It has come to our attention that in figure 3 of BE Baysal et al (J Med Genet 2004;41:703-9) that some of the lines were displaced. Below is a corrected figure. The journal apologises for this error.

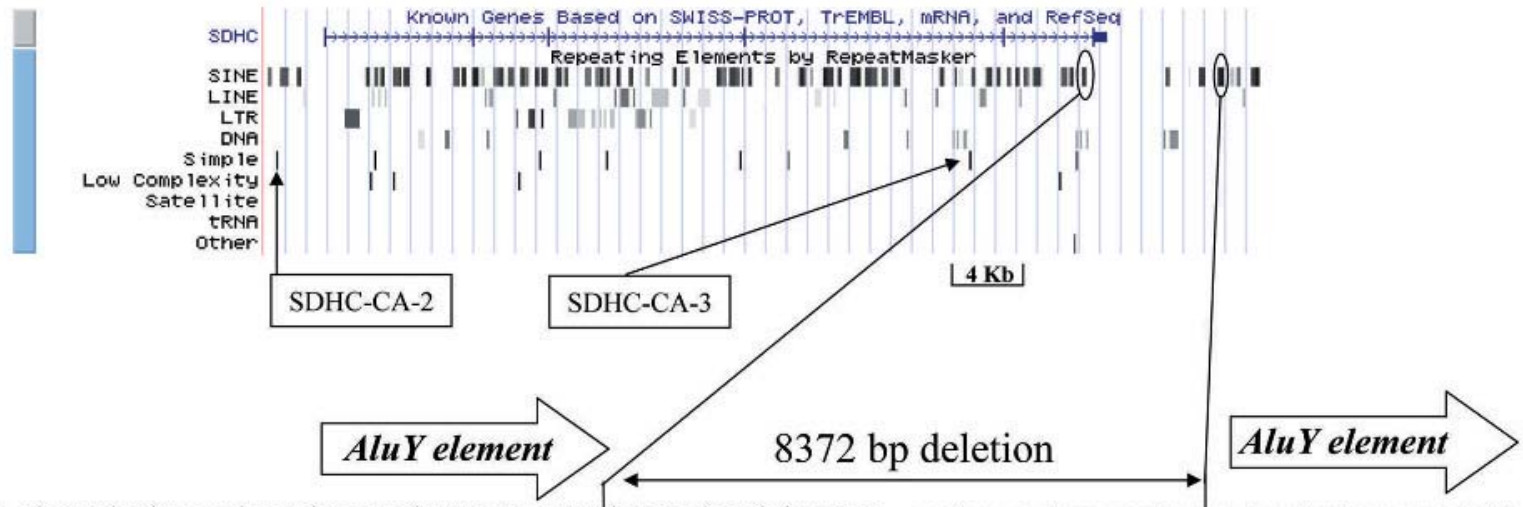

NORMAL ctgagatcatgccactgcactccagcctgggcgacagag tgagagtccgtctcaaaaa... aggtcaggagatcgagaccatcct ggctaacatggtgaaaccccatctctacta

DELETED
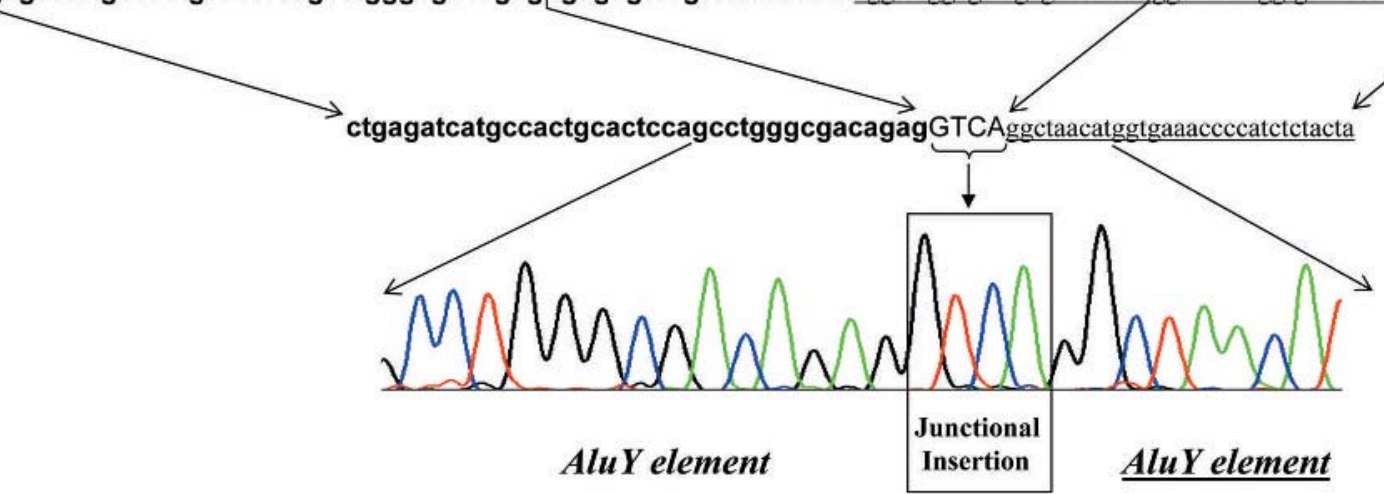

Chromatogram of the deletion junction 